\title{
Maria inventa o mundo
}

\author{
Maria makes up the world
}

\author{
PATRÍCIA PITTA \\ DELFOS - Porto Alegre - Rio Grande do Sul - Brasil
}

\begin{abstract}
Resumo: O diálogo entre o percurso pessoal e a obra literária da escritora Maria Dinorah, com base nos conceitos de Paul Ricoeur sobre a narrativa, considerando os postulados sobre a escrita memorialística, constitui o tema do estudo que ora se propõe. Três textos de inclinação, essência ou cunho autobiográfico, Simplesmente Maria, Apenas uma menina e Vida fragamentada, compõem o corpus da análise.
\end{abstract}

Palavras-chave: Literatura; Memória; Maria Dinorah Luz do Prado

Abstract: The subject of the essay is the personal history and literary work of the writer Maria Dinorah, according to Paul Ricoeur's theories, considering the studies of the memorialistic narrative. Simplesmente Maria, Apenas uma menina e Vida fragmentada are the texts analyzed.

Keywords: Literature; Memory; Maria Dinorah Luz do Prado

A preocupação em preservar registros representativos de uma cultura existe desde a Antiguidade. Atualmente, alocados em institutos culturais, fundações ou universidades, os acervos literários dão conta de boa parte desse anseio. Constituindo-se como fonte documental e de pesquisa, os arquivos dos escritores mobilizam olhares de acadêmicos, leitores e aficionados sobre a obra literária, seu processo criativo e seu alcance sociocultural. Os materiais que compõem os acervos - manuscritos, rascunhos, esquemas, cartas, fotos, documentos, publicações - cercam-se de uma áurea de fascínio que se relaciona à promessa de acesso à intimidade, aos segredos da obra e de seu autor. É, portanto, dessa possibilidade do desvendamento das intencionalidades, das operações envolvidas na arquitetura da obra de arte e de sua repercussão que surge o encantamento que envolve o contato com os acervos.

Convertendo-se em espaços privilegiados, os acervos literários oferecem condições fundamentais para o diálogo entre os complexos processos de transformação do fenômeno criativo quando proporcionam ao pesquisador encontrar, no lugar de interpretações estáticas, "explicações multicausais, funcionais e estruturais" ${ }^{1}$, em conformidade com as teses de Jauss que "deslocam o foco dos estudos

1 OLINTO, Heidrun Krieger. Interesses e paixões: histórias da literatura. Histórias da Literatura: as novas teorias alemãs. Rio de Janeiro: Ática, 1996.

2 MOREIRA, Maria Eunice. História da Literatura: alguns problemas e (in) certas propostas. Papéis nada avulsos. Porto Alegre: Edipucrs, 2012, p. 13. de literatura para outras esferas que não sejam somente aquelas centradas no texto literário"2. A interpretação de uma obra à luz de sua documentação primária, seu prototexto $^{3}$, liberta, então, da obsessão pelo "gênio", dos possíveis delírios da análise exclusivamente simbólica e de qualquer leitura vagamente psicobiográfica, ao apresentar um "novo" texto, vivo, vibrante, esperançoso, delicado, mas, essencialmente, múltiplo.

Examinar o acervo de um escritor, ler seus manuscritos, seus registros e esquemas, leva ao abalo de saberes e de perspectivas sobre o texto, sobre o autor e seu contexto, sua obra, enfim, sobre o processo criativo, artístico e cultural em geral, abrindo todo um universo de novas possibilidades analíticas e produtivas. Perseguir o devir de uma criação literária, avaliando os traços de sua gênese, significa recriar seu mundo, aquilo que foi estabelecido, explorando verdades arraigadas, em busca de novos parâmetros, perspectivas e esclarecimentos.

Embora esse prazer esteja ameaçado pela atual sistemática da produção literária, visto que o advento e a difusão de tecnologias digitais desobrigam o autor a registrar os rastros de sua obra, muito material ainda se encontra intocado em acervos e vários ainda são os autores que mantém o hábito de arquivar seus registros.

\footnotetext{
3 O termo foi proposto e também definido por Jean Bellemin-Nöel na obra Le text et l'Avant-texte, Paris: Larousse, 1972. Prototexto [Avanttexte]: conjunto constituído pelos rascunhos, manuscritos, provas e outras variantes que precedem à obra materialmente.
} 
O DELFOS - Espaço de Documentação e Memória Cultural, inaugurado em 2007, é o local de conservação, reconhecimento e manutenção da memória (como o próprio nome diz), da Pontifícia Católica do Rio Grande do Sul em Porto Alegre. Documentos variados, como agendas, cartas e fotos, originais, publicações, textos inéditos, fortuna crítica e muitos outros, organizados em mais de quarenta acervos, resgatam e mantém viva a história literária e sociocultural do sul do Brasil. De caráter linguístico, literário, histórico, jornalístico e arquitetônico, tais acervos abrigam material de pesquisa extremamente rico, que aguarda pesquisadores de áreas afins para seu exame e divulgação. Dentre os autores cujos documentos se encontram sob a custódia do DELFOS está a escritora sobre a qual por ora o olhar se concentra: Maria Dinorah Luz do Prado, notável criadora e pensadora da literatura sul-rio-grandense. O espólio relativo à sua vida literária foi doado por seus herdeiros à Biblioteca Central Irmão José Otão da PUCRS em 2009.

Professora por formação, jornalista por carisma, contadora de histórias, ativista cultural e escritora, Maria Dinorah Luz do Prado (1925-2007) foi uma das primeiras figuras da literatura infantil e infantojuvenil no Rio Grande do Sul a se dedicar tanto à criação artística quanto ao desenvolvimento de sua arte por meio da aproximação dos autores e suas obras aos seus leitores e às escolas. Nascida em Porto Alegre, em 13 de maio de 1925, passou sua juventude em Torres (RS), voltando à região metropolitana no final da década de 1930. Foi alfabetizadora, formou-se em Letras pela Faculdade Portoalegrense de Filosofia, Ciências e Letras, tendo trabalhado como professora de Português e alfabetizadora até o ano de 1989. Foi ainda Coordenadora do Setor de Promoções Culturais da Secretaria de Educação do Estado do Rio Grande do Sul e obteve o grau de Mestre em Literatura de Língua Portuguesa pela Universidade Federal do Rio Grande do Sul em 1978, com a dissertação A literatura infantil de Erico Verissimo, orientada pelo professor Guilhermino Cesar ${ }^{4}$

A produção literária de Maria Dinorah se inicia em Alvorecer $^{5}$ (1944) e acontece, de forma esporádica, em mais duas obras: No tempo e na vida ${ }^{6}$ (1952) e Seara de $\mathrm{Luz}^{7}$ (1962). Depois disso, a autora publicou várias obras, em intervalos de tempo bastante curtos, até a virada do

\footnotetext{
4 http://www.pucrs.br/delfos/?p=prado

5 DINORAH, Maria. Alvorecer. Gravataí: Gráfica Gravataí, 1944.

6 DINORAH, Maria. No tempo e na vida. Gravataí: Gráfica Gravataí, 1952.

7 DINORAH, Maria. Seara de luz. Gravataí: Gráfica Gravataí, 1962.

8 DINORAH, Maria. O Livro infantil e a formação do Leitor. Petrópolis: Vozes, 1995

9 DINORAH, Maria. O livro na sala de aula: uma alternativa em educação e leitura. Porto Alegre: L\&PM, 1987.

10 Poeta francês do Século XX (1907-1988). In: ZULAR, Roberto. Criação em processo: ensaios de crítica genética. São Paulo: Iluminuras, 2002
}

Século XX. A maioria de seus livros é de poesias e de literatura infantil e infantojuvenil, mas Maria Dinorah flertou também com os paradidáticos e com a crítica especializada em $O$ livro infantil e a formação do leitor ${ }^{8}$ e $O$ livro na sala de aula: uma alternativa em educação e leitura9.

Vários prêmios, títulos e homenagens foram-lhe dirigidos, dentre eles o Prêmio Jorge de Lima, pelo livro Geometria de sombra, em 1992, livro que também rendeu o Prêmio Jabuti no mesmo ano. A Associação de Críticos de Arte, a Fundação Nacional Livro Infantil e Juvenil, o Instituto Piaget (Lisboa) e a Feira de Bolonha (Itália) estão no rol das entidades que reconheceram a grandeza de sua produção. A escritora teve ainda a honra de ser a primeira mulher escolhida como Patrona da tradicional Feira do Livro de Porto Alegre em sua 35a edição no ano de 1989.

Com grande atuação na imprensa, Maria Dinorah assinou colunas de crítica literária por anos e colaborou com jornais de diferentes cidades brasileiras, como Folha da Tarde, Diário da Tarde, Jornal do Comércio, Correio do Povo, Lidador, Zero Hora, sendo, inclusive, criadora de suplementos dirigidos ao público infantil. Em 1988 e 1989 organizou e apresentou o Programa Viva o Livro, da Rádio Feplam/RBS, em Porto Alegre, no qual comentava a produção de literatura infantil no País.

Sua obra está situada, por sua recepção e pela história literária sul-rio-grandense, entre as publicações de literatura infantil de maior êxito junto ao público, especialmente o escolar, tendo sido, talvez, a autora gaúcha mais produtiva e a mais lida pelo público infantil. A crítica a inclui entre os melhores escritores brasileiros do gênero da segunda metade do Século XX.

Então, se na fala de René Char "um poeta deve deixar traços de sua passagem, não provas. Somente traços fazem sonhar" "10, a gaúcha Maria Dinorah Luz do Prado é dessas "criaturas criadoras" que nos fazem sonhar. E muito! Sua produção engloba prosa, poesia, literatura infantil, entusiasmo e dedicação. Apaixonada por tudo o que diz respeito ao texto literário, desde a crítica literária, passando pelo esforço pedagógico junto às escolas, pensando a alfabetização, o desenvolvimento do hábito da leitura, e chegando ao ativismo cultural, Maria Dinorah publicou, ao longo de sua vida, mais de cem títulos. Jamais abandonando a "arte de professorar", exerceu o magistério com grande respeito pelo ato de ensinar, ganhou prêmios e honrarias, e ainda reservou muitos outros tantos escritos que começaram a ser descobertos, reabertos, revistos e trazidos ao conhecimento do público, sob os auspícios do CNPq - através da concessão de uma Bolsa de Pesquisa de Pós-doutorado Júnior, PDJ, vigente de outubro de 2013 a setembro de 2015 -, com a colaboração da FALE/PUCRS, na pessoa da supervisora 
de pesquisa Professora Doutora Maria Eunice Moreira, o acolhimento do DELFOS e a anuência dos herdeiros da escritora.

Considerando que no trabalho de investigação de um acervo literário o objeto do olhar tende a ser a literatura in statu nascendi - focalização que obedece a uma vontade de dessagrar, desmistificar o texto tido como "definitivo", ampliando-o em novas construções de sentido -, os manuscritos, como incipiência das obras, enquanto suporte material, são, portanto, um lugar de memória, mas também - e nesse caso, principalmente - um espaço de inscrição. Maria Dinorah, com seu apreço pelo registro e recolha dos documentos de sua produção e vivência literária viabilizou a concretização da ideia de Paul Valéry da obra como um grupo de operações possíveis.

O manuscrito é o lugar onde se inscreve, linha a linha, o duelo do espírito com a linguagem, da sintaxe com os dois, a alternância da espera com a pressa, todo o drama da elaboração de uma obra e da fixação do instável. (...) É o sentimento que tenho diante de tudo que está escrito, que é matéria para remexer, para corrigir e sempre um estado entre outros de certo grupo de operações possíveis. (VALÉRY, 1948, p. 65)

Havendo, então, três aspectos sob os quais o estudo dos prototextos pode incidir, a saber: a noção de texto, a noção de escrita e a de autor, optou-se - embora os registros disponíveis da produção de Maria Dinorah localizados em seu acervo permitam mergulhar em todos e qualquer um - por concentrar o foco de análise na construção da personagem "Maria Dinorah" e na manutenção de sua posteridade elaborada pela própria autora, através de textos seus de inclinação, essência ou cunho autobiográfico descobertos no acervo.

Investigando justamente o diálogo entre o percurso pessoal e a obra literária da escritora, considerou-se também textos seus de natureza crítica, veiculados em jornais e revistas, registros de sua trajetória e produção acadêmica e artigos que relatem sua vivência e seu ativismo cultural disponíveis em seu acervo, relacionando-os à sua obra memorialística, a fim de conhecer os mais variados aspectos pessoais e profissionais de Maria Dinorah para, então, a identificar a interferência de seu percurso de vida sobre a produção literária.

O que inicialmente seria apenas a análise dos textos em prosa Simplesmente Maria, Apenas uma menina e Vida fragmentada ${ }^{11}$, nos quais Maria Dinorah explora de forma transparente e intimista sua trajetória, enfatizando os eventos que transformaram a pequena Maria Shirley Temple Dinorah na Maria Dinorah Luz do Prado, grande dama da literatura sul-rio-grandense (obras que entre si apresentam intenção narrativa e focalização diferentes), posteriormente ampliou-se para a consideração de textos poéticos - em grande quantidade possivelmente inéditos ${ }^{12}$ - pertencentes ao que se denominou Agendas poéticas, conjunto de manuscritos contendo poesias e aforismos regidos pelo sabor dos acontecimentos cotidianos e que foram registrados em agendas de compromisso. ${ }^{13}$

Esta incursão ao universo literário de Maria Dinorah possibilitou que se aprofundasse a questão da narrativa memorialística, reconhecendo que pensar a memória remete, inevitavelmente, à ideia de esquecimento. Os termos que parecem antagônicos são, na verdade, complementares, não podendo mais serem pensados de forma dicotômica. Como afirma Felipe Pena, "no mundo dos megabytes, nunca foi tão fácil armazenar memória, entretanto, a amnésia nunca esteve tão presente". ${ }^{14}$

É em relação a esse movimento duplo e (aparentemente) paradoxal que o medo íntimo da perda da memória se descortina e supervaloriza os registros factuais e vivenciais. Uma fome memorialística sobrevive ao furor destrutivo da Modernidade, dele emergindo junto a leitores que se mostram ansiosos pelas histórias da vida privada, pela apropriação dos foros íntimos e pelo desvelamento do cotidiano que são então, passíveis de serem representadas pela linguagem.

Desde as formulações platônico-aristotélicas, passando pelos escritos de Cícero, Quintiliano, Santo Agostinho, São Tomás de Aquino, Montaigne, Locke e Bergson, o repertório memorialístico é explorado por vários campos de estudo, mas recebe atenção tímida da teoria da literatura. É apenas com Bakhtin, Benjamin e Ricoeur, três grandes pensadores da Literatura - ainda que oriundo das Letras seja apenas o primeiro deles - que, no século XX, o tema começa a receber uma atenção mais consistente dos estudos literários. ${ }^{15}$

Se, como admite Paul Ricouer ${ }^{16}$, a narrativa e a leitura são pressupostos essenciais para a compreensão da história, pois de alguma forma a narrativa está arraigadamente presente em nossa vida ao efabularmos feitos, fatos, fenômenos, sensações na tentativa de traduzir

11 Destes textos, foi encontrada apenas uma edição de Simplesmente Maria, realizada pela Editora Melhoramentos, datada de 1981. De Apenas uma menina e Vida fragmentada não foram encontradas edições, somente os originais datiloscritos disponíveis no acervo de Maria Dinorah no Delfos/ PUCRS, o que indica serem esses dois textos inéditos.

12 Devido ao enorme número de textos manuscritos encontrados e o tempo de vigência da bolsa de pesquisa, muitos, mas não a totalidade dos textos, puderam ser devidamente selecionados como originais e inéditos.

13 Por estar o acervo ainda não-catalogado, foi possível a descoberta de tal conjunto de textos, juntamente com aproximadamente duzentos cadernos manuscritos, que na sua maioria trazem poesias, algumas "histórias infantis" (como denominava a própria escritora) e alguns poucos contos.

14 PENA, Felipe. Teoria da biografia sem fim. Rio de Janeiro: Mauad, 2004 p. 20.

15 MITIDIERE, André. Vidas e varões enovelados: como e porque des(ler) os clássicos da biografia. 306 fls. (Tese de Doutorado). Porto Alegre: PUCRS, PPGL/FALE, 2008. Disponível em: <http://http://repositorio. pucrs.br/dspace/bitstream/10923/4113/1/000400158texto\%2BComple to-0.pdf>. p. 232

${ }^{16}$ RICOEUR, Paul. Temps et récit. Paris: Seuil, 1983. 
sentimentos, o ato de narrar constitui uma dimensão fundamental da comunicação humana e, conforme Victor Turner ${ }^{17}$, atribui significado ao mundo, pois é no enredo que o sentido cultural é construído. Então, é a arte de narrar que se origina na experiência que leva o conhecimento ao homem.

Considerando que o objetivo maior da narrativa memorialística é gerar conhecimento sobre o passado de alguém, uma postura reflexiva é a condição primeira do biógrafo, uma vez que a revisão dos seus próprios conceitos, simulacros e estereótipos deve preceder a tarefa de reconstrução pela linguagem de uma trajetória de vida. Diana, Damasceno Lima Silva, destaca:

(...) escrever biografias em nossos dias requer consciência aguda do processo de reinterpretar o passado como forma particular de construção, sujeita a variados desdobramentos, levando em conta que vidas podem ser entendidas como sistemas complexos. (SILVA, 1999, p. 97)

Mas, com todas as possíveis imperfeições do processo de escrita, as deformações, obliterações e o esquecimento implicados, o relato de vivências sobrepõem-se à esfera pública da história, não como um gênero universal literário, mas como um gênero híbrido, no qual a história e a historiografia, a literatura e a biografia, a história da literatura e a teoria da literatura se enfrentam numa dinâmica de recepção e transmissão. Isso porque o ato de narrar uma vida se reformula recorrentemente ao passo em que se ampliam as interrogações impostas pela observação do objeto-sujeito. Reside nesta particularidade uma das mais notórias dificuldades para a composição de uma biografia: unir as diversas e variadas peças, que podem ser também desconexas, numa construção textual que as organize em torno de um enredo.

Por se tratar de uma tessitura delicada, na qual "universos entranham-se e às vezes até se estranham"18, algumas considerações acerca da biografia fazem-se necessárias.

Biografia é, a rigor, uma compilação dos elementos que caracterizam uma trajetória de vida que inter-relaciona metodologias e saberes diversos em sua práxis, fazendo-se um construto simbólico. Com isso, o trabalho do biógrafo é uma especialidade à parte, sem especificidade restrita. Para biografar, basta fazer-se biógrafo, pois não há uma formação que conceda a "arte" ou a "ciência" da biografia. Não há exigência de que o biógrafo seja jornalista, antropólogo, literato ou historiador.

Embora a biografia seja uma categoria indizível em si, um atributo se delimita: a narrativa biográfica, na condição de gênero literário, caracteriza-se como "não-ficção". Da literatura, a biografia se aproxima por ter também como foco o elemento humano, e por se apropriar de seu conjunto de técnicas, de seu artesanato e de sua materialidade, mas, embora isso confira status de criação, "é criação histórica, não romanesca" ${ }^{19}$ Sendo o relato de uma vida humana, uma existência real, a partir dos materiais disponíveis sobre ela, a biografia exclui os dois extremos do espectro biográfico, a saber, a biografia novelada e a biografia erudita. ${ }^{20}$ A primeira, por priorizar a eficácia da narração, pecando facilmente contra a fidelidade do relato, e a segunda, pela falta de uma narrativa que compacte os dados e a documentação disponíveis sobre o sujeito biografado de forma coerente e satisfatória em um enredo conciso.

Em seus postulados, Philippe Lejeune ${ }^{21}$ apresenta aporte teórico para que o espaço biográfico e a narrativa biográfica literária sejam visualizados como entrelugares, circundados pela poética, pela história e pela literatura, como também pela filosofia, pela pedagogia, pela retórica, pela semiótica, pela psicanálise, pela sociologia e todo e qualquer campo que se mostrar produtivo ao intuito do ato de narrar. Conforme explica Anna Caballé, da literatura, a narrativa; da história, a vida humana; e da psicologia, o desvelo. Disso se faz a biografia (informação verbal ${ }^{22}$ ). E é apoiado em dois procedimentos fundamentais: o indutivo que opera a partir das estruturas documentais geradas pelo indivíduo - imagens, memórias, testemunhos... - e que permitem, quando muito, reconstruir o que se passou; e o dedutivo, inspirado em todos os âmbitos da experiência humana que podem vir a ajudar a compreender ao indivíduo passível de ser biografado, que o relato biográfico deve ser arquitetado. "La biografía necesita de ambos procedimientos, pero em un equilibrio particularmente delicado". ${ }^{23}$

A autobiografia, por sua vez, é uma forma mais complexa de biografia, pois, sendo ela o relato do autor sobre suas vivências, deve ser composta por discurso referencial e autêntico, no qual o enunciador se compromete com a veracidade e a sinceridade dos fatos

17 TURNER, Victor: Social Dramas and Stories about Them. Critical Inquiry. The University of Chicago Press Stable, 1980, p. 141-168.

18 VILAS BOAS, Sérgio. Biografias \& biógrafos: jornalismo sobre personagens. São Paulo: Summus Editorial, 2002, p. 11.

19 LINS, Álvaro. Teoria literária: poesia, romance, teatro, biografia, crítica. Rio de Janeiro: Edições de Ouro, 1967, p. 87.

${ }^{20}$ CABALLE, Anna. Biografia y punto de vista: perspectivas actuals. Fala proferida em II Reunión de la Red Europea sobre Teoría y Prática de la Biografía. Le singulier et le collectif à l'épreuve de la biographie. Paris, 9-8 de enero. Disponível em: <http://www.uv.es/retpb/docs/Texto\%20 Caballe.pdf>. Data de acesso: 02/04/2015.

${ }^{21}$ LEJEUNE, Philippe. Le désir biographique. Cahiers de Sémiotique Textuelle. Paris, n. 16, 1989.

22 Fala proferida na disciplina Escrita Memorialística Contemporânea, no Programa de Pós-graduação em Letras da PUCRS em abril de 2015.

${ }^{23}$ CABALLE, Anna. Biografia y punto de vista: perspectivas actuals. Fala proferida em II Reunión de la Red Europea sobre Teoría y Prática de la Biografía. Le singulier et le collectif à l'épreuve de la biographie. Paris, 9-8 de enero. Disponivel em: <http://www.uv.es/retpb/docs/Texto\%20 Caballe.pdf>. Data de Acesso: 05/04/2015 
narrados. (Informação verbal ${ }^{24}$ ). Se por muito tempo, tal modalidade textual foi pouco explorada e até menosprezada, pois a crítica literária estava convencida de que Albert Thibaudet ${ }^{25}$ tinha razão ao afirmar que "a autobiografia é a arte dos que não são artistas, o romance dos que não são romancistas" ${ }^{26}$, é bem verdade que, mesmo com alguns avanços no reconhecimento de sua especificidade, a autobiografia ainda é vista como inútil, narcisista e insossa ${ }^{27}$.

Poucos são os estudiosos do tema e em menor número ainda os que reconhecem o seu mérito. Dentre tais pensadores, destaca-se Philippe Lejeune, que se estabelece como principal teórico francês especialista em autobiografia e uma referência mundial sobre o assunto ao elaborar a base atual sobre a qual se busca compreender o gênero autobiográfico. É dele a delimitação de literatura autobiográfica melhor aceita no mundo acadêmico literário em língua latina: "Narrativa retrospectiva em prosa que uma pessoa real faz de sua própria existência, quando focaliza sua história individual, em particular a história de sua personalidade" (LEJEUNE, 2008, p. 15).

Segundo seus postulados, um texto autobiográfico não pode ser definido pela forma (relato), tampouco por seu conteúdo (vivência humana), pois essas características o aproximam obviamente do texto ficcional. A diferença, conforme o pensador francês, é marcada pelo que denominou pacto autobiográfico, conceito que corresponde ao compromisso que um autor assume ao contar diretamente sua vida (ou uma parte, ou um aspecto dela) num espírito de verdade. ${ }^{28}$

Uma autobiografia não é apenas um texto no qual alguém diz a verdade sobre si próprio, mas um texto em que alguém real diz que a diz. E este compromisso produz efeitos particulares sobre a recepção. (LEJEUNE, 2013, p. 538)

O primeiro ensaio de Philippe Lejeune, 1975, foi revisto após 25 anos, 1996, e seguiu sem apresentar novas conclusões sobre as maiores questões levantadas pelos estudos acadêmicos acerca da autobiografia, a saber: qual a identidade do autor? Qual a confiabilidade do relato? Qual seu valor literário? Quem é o autor, sociologicamente? Já em seu terceiro ensaio sobre o

\footnotetext{
${ }^{24}$ Fala proferida na disciplina Escrita Memorialística Contemporânea, no Programa de Pós-graduação em Letras da PUCRS em abril de 2015

25 Discípulo de Henri Bergson, foi p principal crítico literário francês do período entre as duas guerras mundiais (1874-1936).

${ }^{26}$ LEJEUNE, Philippe. Da autobiografia ao diário, da Universidade à associação: itinerários de uma pesquisa. Letras de Hoje, Porto Alegre, v. 48 , n. 4 , out.-dez. 2013 , p. 538

27 Idem.

${ }^{28}$ LEJEUNE, Philippe. Signes de vie. Le pacte autobiographique 2. Paris: Seuil, 2005.

${ }^{29}$ RICOEUR, Paul. La mémoire, l'histoire, l'oubli. Paris Editions du Seuil, 2000.
}

assunto, O pacto autobiográfico 25 anos depois, 2001, é possível compreender como a literatura autobiográfica pode ser interpretada sob uma perspectiva de pacto autobiográfico:

... no pacto autobiográfico, como, aliás, em qualquer contrato de leitura, há uma simples proposta que só envolve o autor: o leitor fica livre para ler ou não e, sobretudo, para ler como quiser. (LEJEUNE, 2008, p. 15)

Considerando então, tais dúvidas oriundas do século $\mathrm{XX}$, que colocam em foco os conceitos fundamentais da escritura autobiográfica - a representação linguística, o sujeito autônomo, a vida íntegra -, novos aportes teóricos se somam com a pretensão de possibilitar o entendimento do fenômeno da autobiografia. Deles, a instância que ora se dimensiona é a do sujeito, consciente de si, em posse de uma memória íntegra de sua vivência e capaz de englobar seus elementos constitutivos em uma narração. E aqui ao se reconhecer um dilema teórico frente a desconexão substancial entre o sujeito que escreve, o que lembra e o que vivenciou o fato narrado, busca-se em Paul Ricoeur ${ }^{29}$ um desembraço desses três elementos por meio de sua perspectiva hermenêutica.

Aceitando a relevância das questões referentes à estruturação interna da obra literária, mas recusando a concepção imanentista da literatura, a hermenêutica de Ricoeur não se apresenta somente como uma alternativa metodológica, dentre outras, de interpretação do texto literário, para ele, a identidade do ser humano é, sobretudo, narrativa.

Paul Ricoeur (1913-2005) foi um dos grandes pensadores que despontaram no século XX, no período pós II Guerra Mundial. Hermeneuta, mas descendente da fenomenologia, seus estudos concentram-se na linguagem e compõem uma teoria da interpretação que tem fundamento em uma ontologia da escrita. Conforme sua perspectiva, então, o homem se expõe e se constrói pela linguagem. Ao integrar fenomenologia e hermenêutica, Ricoeur chega ao que há de comum em todas as disciplinas humanas: narração e temporalidade. Em vista disso, define a interpretação como a dialética da compreensão/explicação no plano do sentido imanente ao texto.

Acadêmico da Sorbonne (França), Louvain (Bélgica) e Yale (EUA), as escolhas intelectuais de Ricoeur o levaram a circular por áreas como a linguística, a psicanálise, o estruturalismo, mas o fundamento de sua filosofia emerge realmente do existencialismo de Gabriel Marcel (1889-1973) - que, inclusive, foi seu professor; do personalismo de Emmanuel Mounier (1905-1950) e da fenomenologia de Edmundo Husserl (1859-1938).

A suposta complexidade de seu pensamento pode ser creditada à tentativa de conciliação dessas correntes 
basicamente opostas da filosofia contemporânea em prol de um pensamento mais abrangente, produzindo uma renovação do pensar filosófico que lhe permitiu afirmar o trabalho de interpretação como mais do que uma simples captação do sentido dos textos e de seus símbolos, como um mecanismo de compreensão do ser, do mundo e do próprio ser no mundo.

A hermenêutica do si, a priori, faz desviar a reflexão mediante a análise, pois a teoria da linguagem e a teoria da ação indicam que a constituição do si não está completa de início e a identidade não é plenamente pessoal. Tal desvio se estabelece com o esclarecimento do termo identidade, pois sua equivocidade não raras vezes conduz a enganos e aporias, que Ricoeur buscou solucionar por meio da teoria da narrativa, pensando-a como um espaço inventivo que possibilita a construção/compreensão do si mesmo no tempo.

Incluindo em suas preocupações a ética, a moral e a política, o filósofo francês afirma que o homem participa de duas dimensões: a social e a moral. Em ambas o que define o sujeito é a linguagem, pois possibilita o pensar e o interpretar; o exprimir o mundo; e a instituição do indivíduo.

Para considerar o sujeito social, Ricoeur constrói o conceito de mesmidade e para delinear o sujeito moral, autônomo e independente, elabora o conceito de ipseidade. A identidade-idem, a mesmidade, corresponde à identidade que permanece no tempo, que se liga ao grau mais elevado de significado. A ela se opõe o diferente, no sentido do mutável, variável, a identidade-ipse, a ipseidade.

No nível ontológico, a hermenêutica do si apresenta a alteridade e mostra que a identidade apenas será autenticamente pessoal quando envolver a responsabilidade para assumir conflitos que se mostram e buscar a sua superação, seja no foro íntimo ou nas relações interpessoais. O si é, portanto, o sujeito que se responsabiliza pela dialética de sua identidade, no estabelecimento de seu caráter, idem, e na regulação de sua palavra promessa, ipse. O si é quem acompanha a história de suas mudanças, sendo palco da experiência da alteridade; é o sujeito que é agente de suas ações, e paciente no êxito ou no fracasso dos outros. Portanto, a perspectiva ricoeuriana de mesmidade dá conta daquilo que torna o sujeito um ser social, membro da espécie humana, tendo relevância, desta forma, categorizar $\mathrm{o}$ indivíduo, estabelecendo núcleos sociais, rótulos e parentescos. Complementarmente (e não opostamente), a ipseidade é o que demarca o sujeito em relação a todos os outros indivíduos da sociedade, conferindo-lhe singularidade através de características que o tornam único e insubstituível. É nesta dialética entre idem e ipse que se edifica também a identidade autoral.
Então, ipseidade é a faceta do sujeito que o qualifica como singular, como um ser único distinto de qualquer outro, e para o estabelecimento dessa distinção, as narrativas são imprescindíveis. As narrativas, como história de vida contada pelo indivíduo, aquilo que o torna exclusivo, e as promessas, como o elo entre a fala e a ação a ela correspondentes, são os construtores do si. E, conforme tais postulados, é possível, então, compreender o indivíduo pelo modo de sua fala, seu conteúdo, sua relevância e a ação a ela relacionada.

Reconhecendo a influência do meio, seja pela origem ou pela ação da educação/construção formal, e das escolhas individuais na formação do si-mesmo, Ricoeur propõe uma construção íntima pautada pelo apreço por si próprio, considerando a linguagem, a história pessoal e a coincidência entre fala e ação.

Assim, por meio desses suportes teóricos, os textos Simplesmente Maria, Apenas uma menina e Vida fragmentada foram lidos e examinados em busca da identidade autoral da escritora gaúcha. Vislumbrou-se, por fim, que a personagem Maria Dinorah foi construída por um si solo fértil de germinação de um ipse que se posiciona ética, moral e politicamente em busca do estabelecimento de uma marca indelével de sua existência.

Os textos Simplesmente Maria, Apenas uma menina e Vida fragmentada são exemplos de um pensar mais bem elaborado que possibilita vê-los tanto como obras acabadas quanto como um processo de construção no qual o resultado é o sujeito que se mostra produtor e produto de si mesmo.

Simplesmente Maria é um livro sutilmente autobiográfico, no qual a narradora conta suas vivências, expõe suas essencialidades e compartilha sentimentos sob uma focalização suave e pueril. A autora perpassa todos os textos que o compõe com seu carisma de literata e os predicados de sua personalidade. Ficando nítida a memória prodigiosa de Maria Dinorah, o mundo maravilhoso que se descortina sob o olhar de uma criança é o melhor resumo desta obra. Sua marca é também uma marca de Maria Dinorah: a leveza.

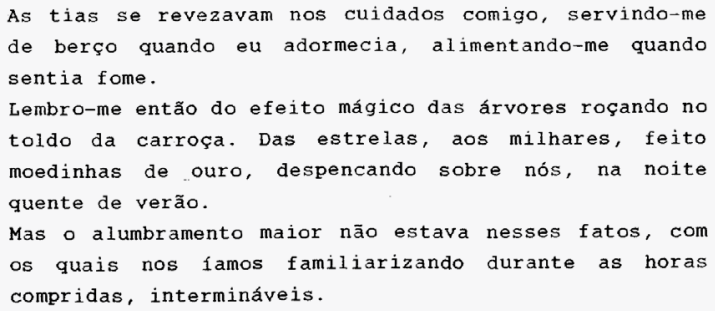

Simplesmente Maria. Fac-símile, p. 24. Acervo Maria Dinorah - DELFOS (PUCRS) 
As memórias narradas em Simplesmente Maria, não seguem uma ordem linear e muito das lembranças são "enfeitadas" por uma alegria contagiante:

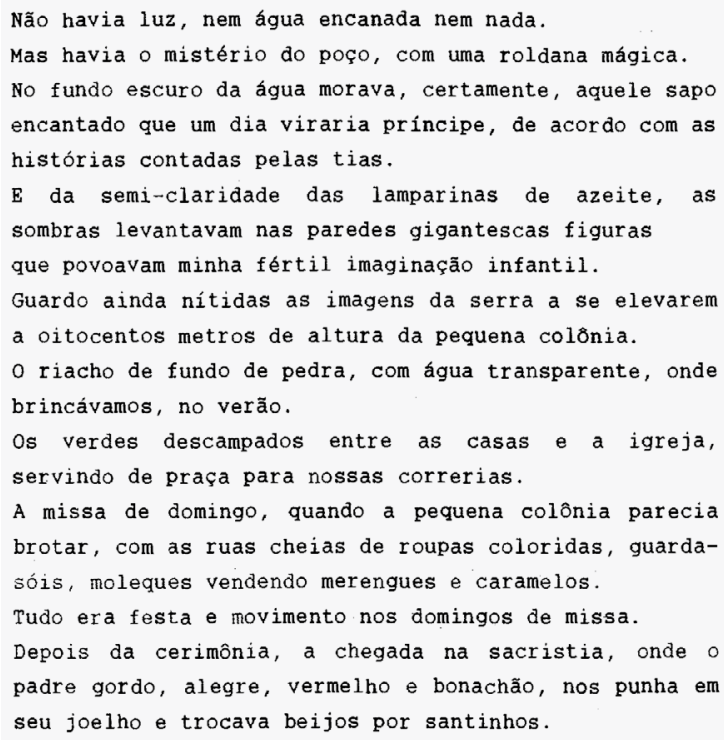

Simplesmente Maria. Fac-símile, p. 9. Acervo Maria Dinorah - DELFOS (PUCRS)

No capítulo Nova Mudança, Dinorah relata com grande vibração suas impressões ao primeiro contato com os livros:

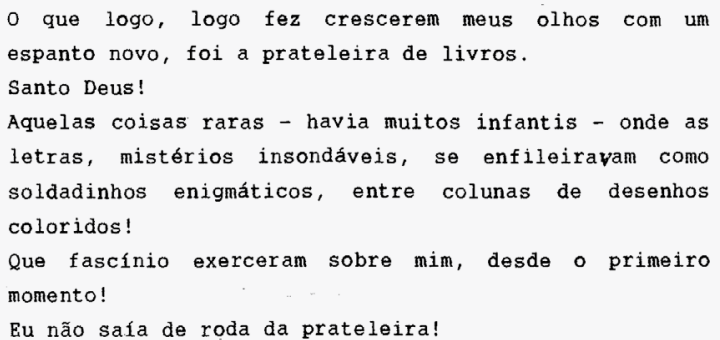

Simplesmente Maria. Fac-símile, p. 24. Acervo Maria Dinorah - DELFOS (PUCRS)

A obra Apenas uma menina, traz uma narradora "garota", cujo domínio sob as coisas do mundo começa a se ensaiar. Ainda um olhar esperançoso conduz a narrativa, mas uma gravidade ou densidade nas avaliações passam a ser delineadas. A criança de Simplesmente Maria está crescendo. O mundo ainda é lugar de cor e brilho, porém as sombras já se mostram e inquietam. Não é de forma alguma um relato sombrio. Apenas mais denso em relação ao olhar infantil constatado no texto examinado anteriormente. Já nas primeiras palavras, Maria Dinorah estabelece o tom da obra:
Sou apenas uma menina.

Mas tenho muitos sonhos.

O mundo, lá fora, sei vagamente que não é fácil.

Há ameaça de guerra, fome, violência e morte.

Mas sou uma menina, por enquanto. E tenho sonhos.

Que sonhos?

Às vezes vôo, como aquela gaivota. Longe, longe.

Nem sei o que é o horizonte, mas há um mistério nele que pressinto inundar-me de promessas.

Estou na quinta série e tenho doze anos.

De imediato, penso em ser professora.

Depois, filosofia, quem sabe.

Sim, algo me diz estar nela a chave do mistério que me aflige, encanta, imanta.

Mas sou apenas uma menina.

Apenas uma menina. Inédito, p. 3. Acervo Maria Dinorah - DELFOS (PUCRS)

Vida fragmentada, por sua vez, é um texto autobiográfico preenchido de poesias que recuperam os afetos, as emoções e as sensações que dirigiram o percurso da escritora, da mulher e da mãe Maria Dinorah. Em tom intimista, rico em lirismo, poema e prosa se combinam costurando a montagem caleidoscópica da narrativa. Embora declaradamente não afeita à experimentalismos, em Vida fragmentada, Maria Dinorah rompe suas regras e escreve o mais excêntrico de seus textos. Nesta obra, a narradora parece não estar preocupada em narrar fatos, vivências, sensações ou perspectivas; ela parece estar sedenta por reter a memória. Não parece interessada em compartilhar, mas sim em registrar enfatizando suas lembranças e impressões. O colorido do mundo se dilui em realidades. Uma voz madura substitui as vozes brandas dos demais textos. Não é um texto sombrio, de forma alguma. Porém, o tom solar das narrativas Simplesmente Maria e Apenas uma menina dá lugar a uma energia lunar, que emana da mulher e da mãe, experimentada e consciente de sua finitude.

\section{À guisa de prefácio}

Nessa 'experiência de vida' onde fala mais alto a PALAVRA, vivência, criação, compromisso - não pretendemos a 'coerência explícita', mas a proposta da vida como ela é: contraditória e controvertida. Fragmentada.

E, reunindo sementes deste ser/não-ser, construir alguma permanência no eterno/perecível do tempo. Afinal, fragmentos também são elos.

Que sejam abraçados como tal.

A autora

Vida fragmentada. Inédito, p. 2 Acervo Maria Dinorah - DELFOS (PUCRS)

É constante neste texto uma narradora que dança com um eu-lírico quase delirante, descrevendo fatos, visões e sensações de forma visceral. O narrar e o cantar 
se entrelaçam dando a dimensão de como Maria Dinorah abordava o ver, o sentir, o viver:

Meu primeiro impacto nesta nova morada foi, certamente, o verde mar.

Um espanto azul incrível, no murmúrio de suas ondas de rendas brancas a lamberem os rochedos imóveis, eternos...

Foi nele, talvez, que esta sensação de infinito e distância se impregnou em mim.

Em seus poentes de fogo, os pescadores iluminavam as redes, poetas cantavam imprevisíveis mistérios e namorados segredavam encantos de ternuras e bemquerenças...

Mar de Maria,

maresia minha.

Verde mar de ver-se, ser-se, ter-se.

Corpo na onda, cor.

Corte,

na gana que afoga o ser. -

Canto, -

onde afogo a fúria, o cansaço,

e este espanto que me converte

de tanto ver, inerte.

Mar de Maria,

maresia minha!

Vida fragmentada. Inédito, p. 2. Acervo Maria Dinorah - DELFOS (PUCRS)

Embora diferentes em focalização e discurso, as três obras mostram Maria Dinorah em todas as suas características e prioridades. Não só como pensadora, mas também como atriz de sua fala. Maria Dinorah bebeu em todas as fontes possíveis. Ela sorveu todos os "eus" disponíveis a sua volta e os derramou em seus textos com intensidade e maestria.

Reunidas em publicação que em breve será editada, as referidas obras possibilitaram, através de sua análise, a compreensão do diálogo entre a escritora, a professora e a entusiasta da literatura com a menina, em Simplesmente Maria, a garota, em Apenas uma menina, e mulher e mãe, em Vida Fragmentada. Sob a lente da hermenêutica de Paul Ricoeur, foi possível constatar que mesmidade e ipseidade na obra de Maria Dinorah reverberam em prol de uma dialética que mobilize essências. É na busca e no fomento do que é essencial ao texto literário e à vivência humana que Maria Dinorah escritora escreve; professora ensina, e mulher-mãe vive e ama. Seu legado é patrimônio humano e, por isso, digno de ser respeitado e mantido vivo por meio de sua redescoberta e difusão.

\section{Referências}

BELLEMIN-NÖEL, Jean. Le text et l'Avant-texte Paris: Larousse, 1972.

CABALLE, Anna. Biografia y punto de vista: perspectivas actuals. Fala proferida em II Reunión de la Red Europea sobre
Teoría y Prática de la Biografía. Le singulier et le collectif à l'épreuve de la biographie. Paris, 9-8 de enero. Disponível em: $<$ http://www.uv.es/retpb/docs/Texto\%20Caballe.pdf $>$. Data de acesso: 02 abr. 2015.

DINORAH, Maria. Alvorecer. Gravataí: Gráfica Gravataí, 1944 DINORAH, Maria. No tempo e na vida. Gravataí: Gráfica Gravataí, 1952.

DINORAH, Maria. Seara de luz. Gravataí: Gráfica Gravataí, 1962.

DINORAH, Maria. O livro infantil e a formação do leitor. Petrópolis: Vozes, 1995

DINORAH, Maria. O livro na sala de aula: uma alternativa em educação e leitura. Porto Alegre: L\&PM, 1987.

LEJEUNE, Philippe. Le désir biographique. Cahiers de Sémiotique Textuelle. Paris, n. 16, 1989.

LEJEUNE, Philippe. Da autobiografia ao diário, da Universidade à associação: itinerários de uma pesquisa. Letras de Hoje, Porto Alegre, v. 48, n. 4, p. 537-544, out./dez. 2013.

LEJEUNE, Philippe; NORONHA, Jovita Maria Gerheim (Org.). O pacto autobiográfico. De Rousseau à Internet. Belo Horizonte: Editora UFMG, 2008.

LEJEUNE, Philippe. Signes de vie. Le pacte autobiographique 2. Paris: Seuil, 2005.

LINS, Álvaro. Teoria literária: poesia, romance, teatro, biografia, crítica. Rio de Janeiro: Edições de Ouro, 1967.

MITIDIERE, André. Vidas e varões enovelados: como e porque des(ler) os clássicos da biografia. 2008. 306 f. Tese (Doutorado em Letras) - Faculdade de Letras, PUCRS, Porto Alegre, 2008. Disponível em: http:/http://repositorio.pucrs.br/dspace/bitstrea m/10923/4113/1/000400158texto\%2BCompleto-0.pdf.

MOREIRA, Maria Eunice. História da Literatura: alguns problemas e (in)certas propostas. In: MOREIRA, Maria Eunice(Org.). Papéis nada avulsos. Porto Alegre: Edipucrs, 2012, p. 11-20.

OLINTO, Heidrun Krieger. Interesses e paixões: histórias da literatura. Histórias da Literatura: as novas teorias alemãs. Rio de Janeiro: Ática, 1996, p. 15-45.

PENA, Felipe. Teoria da biografia sem fim. Rio de Janeiro: Mauad, 2004.

RICOEUR, Paul. Temps et récit. Paris: Seuil, 1983.

RICOEUR, Paul. La mémoire, l'histoire, l'oubli. Paris: Editions du Seuil, 2000.

SILVA, Diana Cristina Damasceno Lima. Entre múltiplos eus: os espaços da complexidade. 1999. $181 \mathrm{f}$. Tese (Doutorado em Letras) - Departamento de Letras e Artes, PUC-Rio, Rio de Janeiro, 1999. Disponível em: <http://www.dbd.puc-rio.br/ pergamum/biblioteca s/php/login tese.php?flag=1999SILVA D C D L.pdf $>$. Data de acesso: 22/03/2015.

TURNER, Victor. Social Dramas and Stories about Them. Critical Inquiry, Chicago, v. 7, n. 1, p. 141-168, 1980.

VALÉRY, Paul. Comment travailet les escrivans. Paris: Flammarion, 1948

VILAS BOAS, Sérgio. Biografias \& biógrafos: jornalismo sobre personagens. São Paulo: Summus Editorial, 2002.

ZULAR, Roberto. Criação em processo: ensaios de crítica genética. São Paulo: Iluminuras, 2002.

Recebido: 29 de outubro de 2015 Aprovado: 21 de dezembro de 2015 Contato: pmpitta@yahoo.com.br 